\title{
QUALIDADE FÍSICA E FISIOLÓGICA DE SEMENTES DE Eremanthus erythropappus (DC.) MAC. LEISH ${ }^{1}$
}

\author{
OLIVIAALVINAOLIVEIRATONETTI ${ }^{2}$,ANTONIO CLAUDIO DAVIDE ${ }^{3}$, EDVALDOAPARECIDOAMARALDA SILVA $^{4}$
}

RESUMO - Este trabalho teve como objetivo identificar e sugerir métodos para avaliação da qualidade física e fisiológica de sementes de candeia (Eremanthus erythropappus). As sementes utilizadas foram colhidas nos anos de 2001 e 2002, respectivamente nos municípios de Carrancas e Lavras, no estado de Minas Gerais. As sementes foram secas, limpas e guardadas em sacos semipermeáveis, em câmara fria a $5^{\circ} \mathrm{Ce} 60 \%$ de umidade relativa até o início dos experimentos. Para facilitar a identificação de sementes vazias foi desenvolvido protocolo com a utilização de raios-X, combinando potência de radiação (Kv) e tempo de exposição das sementes à radiação (segundos). Para a eliminação das sementes vazias foi realizado experimento utilizando soprador de sementes, tipo South Dakota, combinando as aberturas do aparelho e tempo. Para os testes de germinação, as sementes foram passadas pelo soprador, lavadas em hipoclorito de sódio e colocadas para germinar sobre papel, em gerbox. O primeiro experimento avaliou temperaturas de germinação e foi realizado em mesa termogradiente, o segundo experimento testou sensibilidade à luz e alternância de temperatura e foi conduzida em germinadores tipo Mangelsdorfii. Foram determinadas curvas de embebição, nas condições de $30^{\circ} \mathrm{C}, 20-30^{\circ} \mathrm{C} / 10$ horas de luz e $30-20^{\circ} \mathrm{C} / 10$ horas de luz. O protocolo para avaliação radiológica que melhor permitiu a visualização das estruturas internas da semente foi $30 \mathrm{Kv}$ por 45 segundos. A separação das sementes pelo soprador na abertura 6,0 e tempo de 30 segundos permitiu elevar de 14,75 para 93,37\%, o número de sementes com embrião. Os resultados mostraram que as sementes não apresentam dormência e que, quando eliminadas as sementes vazias, a porcentagem de germinação foi alta. As sementes atingiram a máxima porcentagem de germinação aos 14 dias de embebição e a melhor condição para germinação foi alternância de temperatura de $20-30^{\circ} \mathrm{C} / 10$ horas de luz. Os estudos revelaram ainda que a germinação de sementes desta espécie pode ocorrer na ausência de luz.

Termos para indexação: espécie florestal, raios-x, soprador de sementes, sementes vazias, germinação.

\section{PHYSICALAND PHYSIOLOGICAL QUATILY OF Eremanthus erythropappus (DC.) MAC.} LEISH $^{1}$

\begin{abstract}
This study had the objectives to identify and suggest methods for evaluation of the physical and physiological quality of candeia seeds (Eremanthus erythropappus). The seeds used in the experiments were collected in 2001 and 2002, in the district of Carrancas and Lavras in the State of Minas Gerais. The seeds were dried, cleaned and stored in semi-permeable bags in cold chamber at $5^{\circ} \mathrm{C}$ and $60 \%$ relative humidity until the beginning of the experiments. To make the identification of empty seeds easier, a protocol for x-ray use combining radiation potency $(\mathrm{Kv})$ and time (seconds) of exposition to radiation was developed. To eliminate the empty seeds, an experiment was undertaken using a South Dakota type seed blower combining the opening of the apparatus and time. For the germination tests, seeds were passed through the blower, washed in sodium hypochlorite and placed on paper in gerboxes. The first part was done on a thermogradient table and the second in Mengelsdorfii germinators. The imbibition curves were performed at $30^{\circ} \mathrm{C}$ at
\end{abstract}

\footnotetext{
${ }^{1}$ Submetido em: 12/11/2004. Aceito para publicação em 02/05/2005. Parte da dissertação de Mestrado do primeiro autor no curso de Engenharia Florestal, UFLA, Bolsista FAPEMIG;
}

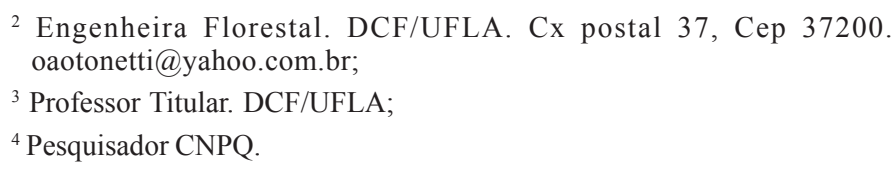


constant light and at $20-30^{\circ} \mathrm{C}$ and $30-20^{\circ} \mathrm{C} / 10$ hours under light. The protocol for radiological evaluation that enabled better visualization of the internal structures was $30 \mathrm{kv}$ for 45 seconds. The separation of seeds by the blower at the opening 6.0 for the time of 30 seconds allowed an increase from 14.75 to $93.37 \%$ in the number of seeds with embryo. The results showed that the seeds did not display dormancy and when the empty seeds were eliminated, the germination percentage was higher. The seeds reached the maximum germination percentage at 14 days of imbibition and the best germination condition was alternate temperature of $20-30^{\circ} \mathrm{C}$ with 10 hours of light. The germination studies revealed that germination also took place in the absence of light.

Index terms: forest specie, x-ray, seed blower, empty seed, germination.

\section{INTRODUÇÃO}

Eremanthus erythropappus, conhecida como candeia, é uma espécie arbórea que pertence à família Asteraceae (Correa, 1984), encontrada em áreas montano-campestre desde do estado da Bahia até o do Rio de Janeiro, em altitudes que variam de 1000 a 1700m (NEMAF, 2003).

O interesse pela espécie deve-se ao óleo produzido pela mesma, extraído de toda a planta. Este óleo, além de outros constituintes, contém alfabisabolol, princípio ativo com propriedades farmacológicas, utilizado principalmente na indústria de cosméticos.

Devido à importância econômica da espécie, tem ocorrido aumento na exploração da candeia, levando a novos plantios, fato que tem proporcionado aumento na demanda por sementes de qualidade. No entanto, pouco se conhece sobre a qualidade de sementes do gênero Eremanthus. Existem informações de que as sementes desta espécie apresentam índices de germinação consideravelmente baixos, porém a causa desta baixa qualidade ainda não foi relatada.

A análise física das sementes pela técnica de raios- $\mathrm{X}$ permite análise rápida das estruturas internas do embrião, alguns tipos de danos mecânicos e de infestação causada insetos (Seed News, 2001; Simak, 1991). Estas informações podem auxiliar na identificação de problemas que influenciam na qualidade física e fisiológica das sementes e que refletem nos índices de germinação das mesmas.

A germinação de sementes envolve uma seqüência de eventos fisiológicos controlada por vários fatores. Cada espécie exige condições específicas para que a germinação ocorra, principalmente quanto à temperatura e presença de luz. A necessidade de flutuação diária de temperatura às vezes ocorre e é freqüentemente observada em sementes de espécies arbóreas, podendo ainda estar associada à exigência de luz, fato comum em espécies que colonizam áreas abertas (Coperland e McDonald, 1999).
Portanto, este trabalho teve como objetivos identificar e sugerir métodos para avaliação da qualidade física e fisiológica de sementes de candeia (Eremanthus erythropappus).

\section{MATERIAL E MÉTODOS}

Origem e beneficiamento das sementes

As sementes foram colhidas em dois anos consecutivos, em altitudes de 1000 a 1250m, nos municípios de Carrancas (MG) - lote 2001 e Lavras (MG) - lote 2002. Os frutos foram deixados ao sol, beneficiados, acondicionados em sacos de papel e levados a sala de secagem $\left(20^{\circ} \mathrm{C}\right.$ e $\left.60 \% \mathrm{UR}\right)$ por 20 dias. Após este procedimento, foram abanados e peneirados. Foram consideradas sementes as unidades de dispersão conhecidas por aquênio. As sementes foram mantidas em câmara fria $\left(5^{\circ} \mathrm{C}\right.$ e $\left.60 \% \mathrm{UR}\right)$, em sacos plásticos semipermeáveis até o início dos testes.

\section{Caracterização dos lotes}

Teste de umidade - Antes de serem levadas para a câmara fria, foi determinada a umidade dos lotes de sementes. $\mathrm{O}$ teste foi feito com quatro repetições de 0,5 grama para cada lote, em estufa com circulação de ar a $103 \pm 2^{\circ} \mathrm{C}$ por 17h (ISTA, 1993).

Pureza física - Para a determinação das sementes puras foi usada a definição proposta pelas Regras para Análise de Sementes (Brasil, 1992), na qual para estruturas de dispersão do tipo aquênio, são consideradas sementes puras: (a) os aquênios e pedaços destes maiores que a metade do tamanho original, a menos que seja óbvio que não contenham sementes e (b) sementes e pedaços das mesmas, maiores que metade do tamanho original, com ou sem o pericarpo. Foram analisadas duas amostras de $1,4 \mathrm{~g}$ para cada lote. O resultado foi dado em porcentagem de sementes puras do lote.

Germinação - As sementes de ambos os lotes foram lavadas em solução de hipoclorito de sódio a $2 \%$ por dois minutos e enxaguadas em água destilada. As amostras foram 
encubadas em germinador à temperatura de $20-30^{\circ} \mathrm{C}$, iluminados por lâmpadas fluorescentes $(20 \mathrm{~W})$, que forneciam 10 horas de luz a $30^{\circ} \mathrm{C}$, seguidas de 14 horas de escuro a $20^{\circ} \mathrm{C}$, em gerbox, sobre três folhas de papel mata borrão. Foram testadas quatro repetições de 50 sementes. O teste teve duração de 15 dias e o resultado foi expresso em porcentagem média de plântulas normais.

Quantificação e separação das sementes vazias

Caracterização da qualidade física das sementes pelo uso de raios- $\mathrm{X}$

Foram utilizadas sementes do lote de 2002, em aparelho de raios-x marca Faxitron, modelo 43855X, nas potências de 10,2030 e $40 \mathrm{Kv}$ e tempos de exposição de 30,45 e 60 segundos. Para a obtenção das imagens foi utilizado filme Kodak MR 2000 (18x24cm).

De acordo com a morfologia interna visualizada nas radiografias, as sementes foram divididas em três categorias: cheias (com embrião bem formado, ocupando todo o interior do aquênio), mal formadas (com embrião ocupando apenas parte do aquênio) e vazias (não continham embrião). Sementes cheias e mal formadas foram denominadas sementes com embrião.

- Germinação das sementes testadas no raio-x Amostras de sementes identificadas pela análise de raios- $\mathrm{X}$ como vazia, cheia e mal formada foram levadas para germinar. $\mathrm{O}$ teste de germinação seguiu a mesma metodologia anteriormente utilizada para avaliação inicial dos lotes.

Separação das sementes - Para separação das sementes com embrião, foi realizado experimento com soprador tipo South Dakota, marca De Leo. Foram determinadas as aberturas do soprador a serem utilizadas. Aberturas abaixo de 2,0 não conseguiram produzir fração leve enquanto aberturas acima de 6,0 removeram todas as sementes para a fração leve. O soprador foi regulado nas aberturas de 2,$0 ; 3,0 ; 4,0$; 5,0 e 6,0 e tempos de ventilação 30 e 60 segundos. Cada tratamento constou de quatro repetições de 2,0 gramas de sementes. Após a separação da fração pesada, a mesma foi limpa manualmente retirando material inerte residual, em seguida as sementes foram pesadas, sendo o peso transformado em porcentagem do peso original. A porcentagem de sementes com embrião na fração pesada foi quantificada pela análise de raios- $\mathrm{X}$, onde foram analisadas 50 sementes de cada fração pesada. Para o lote de 2002 foi determinado o número de sementes por quilograma na condição original e no melhor tratamento de separação, sendo utilizadas oito amostras de 100 sementes, pesadas em balança com aproximação de $0,0001 \mathrm{~g}$.
Os dados obtidos foram analisados pelo programa estatístico SISVAR com probabilidade de $\mathrm{F}<1 \%$ e as médias foram comparadas pelo teste de Tukey a 0,05.

Estudo da germinação

Para o estudo da qualidade fisiológica, foram utilizadas sementes dos lotes já caracterizados, retidas na fração pesada ao passarem por soprador South Dakota, na abertura 6,0 por 30 segundos.

\section{Efeito da temperatura durante a germinação}

$\mathrm{O}$ teste foi conduzido em mesa termogradiente ajustada nas temperaturas de $20,25,30$ e $35^{\circ} \mathrm{C}$, com fornecimento de luz constante. Cada tratamento constou de quatro repetições de 50 sementes, lavadas em solução de hipoclorito de sódio a $2,0 \%$ por dois minutos, enxaguadas com água e distribuídas em gerbox sobre três folhas de papel saturadas com água.

A germinação (protrusão da raiz e formação de plântulas) foi avaliada durante 24 dias e as sementes que não germinaram ao final do teste foram cortadas com bisturi para verificar se estavam mortas, duras ou vazias. A velocidade de germinação (IVG) foi calculada pelo índice de velocidade de germinação das plântulas proposto por Maguirre (Nakagawa, 1994).

Os dados foram analisados pelo programa estatístico SISVAR. Dados de $T_{50}$ e $U_{75-25}$ (uniformidade) foram calculados e analisados a partir do programa Seed Calculator da Plant Research International (PRI) da Universidade de Wageningen, Holanda.

\section{Sensibilidade à luz e temperatura alternada}

Os procedimentos quanto à limpeza, recipiente, substrato e número de sementes por repetição seguiram a mesma metodologia do experimento anterior. As sementes foram colocadas em germinadores regulados nas seguintes condições: $30^{\circ} \mathrm{C}$ com luz contínua, $30^{\circ} \mathrm{C}$ no escuro e $20-30^{\circ} \mathrm{C}$ (10 horas de luz a $30^{\circ} \mathrm{C}$ seguidas de 14 horas de escuro a $20^{\circ} \mathrm{C}$ ). A germinação (protrusão da raiz e plântulas normais) foi avaliada durante 17 dias, sendo a leitura do teste na condição de escuro feita sob luz verde. O IVG da protrusão da raiz foi calculado pela fórmula de Maguirre (Nakagawa, 1994). Os resultados foram analisados pelo programa estatístico SISVAR e os dados de $\mathrm{T}_{50}$ e $\mathrm{U}_{75-25}$ (uniformidade) foram calculados pelo programa Seed Calculator.

\section{Determinação da curva de embebição}

Para as curvas de embebição foi utilizado o lote de sementes do ano 2002. Foi determinada a umidade original, de acordo com a metodologia já citada. As curvas foram elaboradas a partir de duas repetições de $0,05 \mathrm{~g}$ de sementes colocadas para embeber em gerbox, tendo como substrato três folhas de papel mata borrão, saturadas com água destilada. 
As amostras foram acondicionadas em germinadores regulados na temperatura de $30^{\circ} \mathrm{C}$ com luz contínua e temperaturas de $20-30^{\circ} \mathrm{C}$ e $30-20^{\circ} \mathrm{C}\left(10\right.$ horas de luz a $30^{\circ} \mathrm{C}$ seguidas de 14 horas de escuro a $20^{\circ} \mathrm{C}$ ). A cada três horas as sementes eram removidas dos gerbox e pesadas em balança com aproximação de $0,0001 \mathrm{~g}$ até que fossem detectadas as fases I, II e III de embebição.

\section{RESULTADOS E DISCUSSÃO}

\section{Caracterização dos lotes de sementes}

As características originais de umidade, pureza e germinação dos lotes de sementes utilizados encontram-se na Tabela 1. A umidade de equilíbrio das sementes ficou entre 8,0 e $10,2 \%$. O lote de 2001 apresentou $48,60 \%$ de pureza e $15,5 \%$ de germinação e o lote de 2002 apresentou 58,19\% de pureza e $11,5 \%$ de germinação, mostrando que sementes de Eremanthus erythropappus apresentam baixa qualidade no momento da dispersão.

\section{Caracterização da qualidade física das sementes pelo} uso de raios-x

Entre as potências testadas $(10,20,30 \mathrm{e} 40 \mathrm{Kv})$, a potência de $30 \mathrm{Kv}$ permitiu melhor visualização das estruturas internas das sementes, sendo que os tempos de exposição de 45 e 60 segundos favoreceram a distinção das imagens permitindo a identificação das categorias propostas.

Potências abaixo de $30 \mathrm{Kv}$ não registraram imagens bem definidas, enquanto que a potência de $40 \mathrm{Kv}$ permitiu a passagem da radiação com muita facilidade, diminuindo a visibilidade das imagens no filme. A variação de visibilidade e contraste observada pela alteração da potência $(\mathrm{Kv})$ ocorre porque quanto maior o valor de $\mathrm{Kv}$, maior a energia contida no feixe de raios, ou seja maior poder de penetração (Bonzanini Neto, 2003).

O tipo de semente obtida pelo teste de raio-x (cheia, mal formada e vazia) influenciou diretamente na germinação. Pela Tabela 2, pode-se observar que sementes cheias atingiram $87,5 \%$ de germinação considerando plântulas normais, representando incremento de $76,0 \%$ pontos percentuais quando comparadas ao lote original ou sem separação (Tabela 1).

Quanto ao comportamento das sementes mal formadas, pode-se verificar que a germinação, tanto considerando protrusão de raiz quanto plântulas normais, é reduzido em relação às sementes cheias e é provável que dentro desta categoria, algumas se encontravam em estádio mais avançado de desenvolvimento do embrião em relação à outras, visto que foram formadas algumas plântulas. A ocorrência de embriões em diferentes estádios de formação é freqüentemente encontrada em espécies florestais e certamente é devido à desuniformidade de florescimento comum em espécies silvestres, como é ressaltado por Carvalho e Nakagawa (1988) e Machado e Cícero (2003), em estudo sobre morfologia de sementes de Lithraea molleoides.

\section{Separação das sementes no soprador}

O tempo de 30 segundos foi mais eficiente, em relação ao tempo de 60 segundos ao manter mais sementes na fração pesada. O lote de 2002 foi superior no peso de fração pesada ao lote de 2001, como visto na Tabela 3. Ao aumentar a abertura, a fração pesada foi diminuindo até que os resultados das aberturas 5 e 6 se igualaram, não mostrando perda de peso entre estes dois tratamentos (Tabela 3).

A separação em soprador tipo South Dakota ocasionou redução de 3.472 .200 para 1.805 .000 sementes por

TABELA 1. Umidade, pureza e germinação (plântulas normais) dos lotes de sementes de Eremanthus erythropappus utilizados nos experimentos de raios-x e separação de sementes

\begin{tabular}{lccc}
\hline Lote & Umidade (\%) & Pureza (\%) & Germinação (\%) \\
\hline 2001 & 10,2 & 48,60 & 15,5 \\
2002 & 8,0 & 58,19 & 11,5 \\
\hline
\end{tabular}

TABELA 2. Porcentagem de germinação das sementes cheias, mal formadas e vazias para Eremanthus erythropappus (lote de 2002)

\begin{tabular}{lccc}
\hline \multirow{2}{*}{ Critério } & \multicolumn{3}{c}{ Condição das sementes } \\
\cline { 2 - 4 } & Cheias & Mal formadas & Vazias \\
\hline Prot. radícula (\%) & $95,8 \mathrm{a}$ & $21,6 \mathrm{~b}$ & $0 \mathrm{~b}$ \\
Pl. normal (\%) & $87,5 \mathrm{a}$ & $10,8 \mathrm{~b}$ & $0 \mathrm{~b}$ \\
\hline
\end{tabular}

Médias seguidas pela mesma letra na linha são iguais pelo teste de Tukey a $5 \%$.

TABELA 3. Porcentagem de peso da fração pesada para dois lotes de sementes de Eremanthus erythropappus após passarem por soprador de sementes tipo South Dakota (média entre os tempos de 30 e 60 segundos)

\begin{tabular}{ccr}
\hline \multirow{2}{*}{ Abertura do soprador } & \multicolumn{2}{c}{ Lote } \\
\cline { 2 - 3 } & 2002 & 2001 \\
\hline 2 & $50,86 \mathrm{aA}$ & $38,49 \mathrm{bA}$ \\
3 & $24,35 \mathrm{aB}$ & $19,53 \mathrm{bB}$ \\
4 & $15,08 \mathrm{aC}$ & $11,88 \mathrm{bC}$ \\
5 & $12,08 \mathrm{aD}$ & $8,36 \mathrm{bD}$ \\
6 & $10,22 \mathrm{aD}$ & $6,56 \mathrm{bD}$ \\
\hline
\end{tabular}

Médias seguidas pela mesma letra minúscula na linha e maiúscula na coluna são iguais pelo teste de Tukey a 5\%. 
quilograma. A queda na quantidade de sementes por unidade de massa $(\mathrm{Kg})$ mostra que os lotes soprados concentraram as sementes maiores e mais densas, aumentando a qualidade do lote. De acordo com Carvalho e Nakagawa (1988), as sementes mais densas foram mais bem nutridas e superaram em densidade aquelas que foram formadas mais tardiamente. Vários autores citados por Souza et al. (2001) afirmam que sementes mais densas de várias espécies estudadas mostraram melhor desempenho em testes de viabilidade e vigor. Isto também foi observado em sementes Matricaria chamomilla (Nóbrega et al., 1995) quando foram comparadas sementes sopradas em Soprador General Seed Blower com sementes não sopradas.

Quando analisadas pelo teste de raio-x, sementes provenientes das aberturas 5 e 6 mostraram maior porcentagem de sementes com embrião (Tabela 4), sendo que na abertura 6 foi obtida a melhor separação. Na condição original havia $14,75 \%$ de sementes com embrião, valor inferior ao encontrado por Davide e Tonetti (2003) que foi de 52\% pelo teste de germinação. A diferença entre os dois trabalhos pode ter origem nas características específicas dos lotes estudados, visto que condições ambientais, principalmente durante a fase de formação das sementes podem provocar maior ou menor incidência de sementes sem embrião (Carvalho e Nakagawa, 1988).

\section{Estudo da germinação}

Efeito da temperatura durante a germinação

As temperaturas testadas se situam dentro das temperaturas cardinais para germinação destas sementes, visto que foi observada germinação em todos os tratamentos. A Tabela 5 mostra as médias obtidas para cada lote e critério avaliado. A faixa de temperatura que proporcionou a maior porcentagem de plântulas normais foi de 20 a $30^{\circ} \mathrm{C}$ (Tabela 5 e Figura 1). A germinação (plântulas normais) começou no quarto dia, atingindo os valores máximos em 17 dias em todas

TABELA4. Porcentagens médias de sementes com embrião na fração pesada em cada abertura testada, obtidas pelo teste de raios-x (média entre os lotes de 2001 e 2002)

\begin{tabular}{cc}
\hline Abertura & Sementes com embrião \\
\hline 2 & $15,75 \mathrm{~d}$ \\
3 & $46,87 \mathrm{c}$ \\
4 & $81,25 \mathrm{~b}$ \\
5 & $90,25 \mathrm{ab}$ \\
6 & $93,37 \mathrm{a}$ \\
\hline
\end{tabular}

Médias seguidas pela mesma letra na coluna são iguais pelo teste de Tukey a $5 \%$. as temperaturas utilizadas (Figura 1). O IVG das plântulas mostrou que houve maior número de plântulas emergindo por dia a $30^{\circ} \mathrm{C}$ (Tabela 5), o que é confirmado pelo $\mathrm{T}_{50}$ que mostrou os menores valores a $30^{\circ} \mathrm{C}$, indicando maior velocidade do processo germinativo (Tabela 6 ).

$\mathrm{Na}$ maioria das situações estudadas, o tratamento com temperatura de $30^{\circ} \mathrm{C}$ apresentou melhores resultados, no entanto, observa-se que ao longo da germinação, em alguns casos, temperaturas mais baixas, favoreceram o início da germinação (Figura 1). De acordo com Coperland e McDonald (1999), isto pode ocorrer, pois a cada fase da germinação pode haver mudança na temperatura ótima, visto que o processo germinativo é uma série de etapas onde cada uma apresenta características distintas. Isto também é observado ao se comparar o $\mathrm{T}_{50}$ e $\mathrm{U}_{75-25}$ das temperaturas mais baixas e
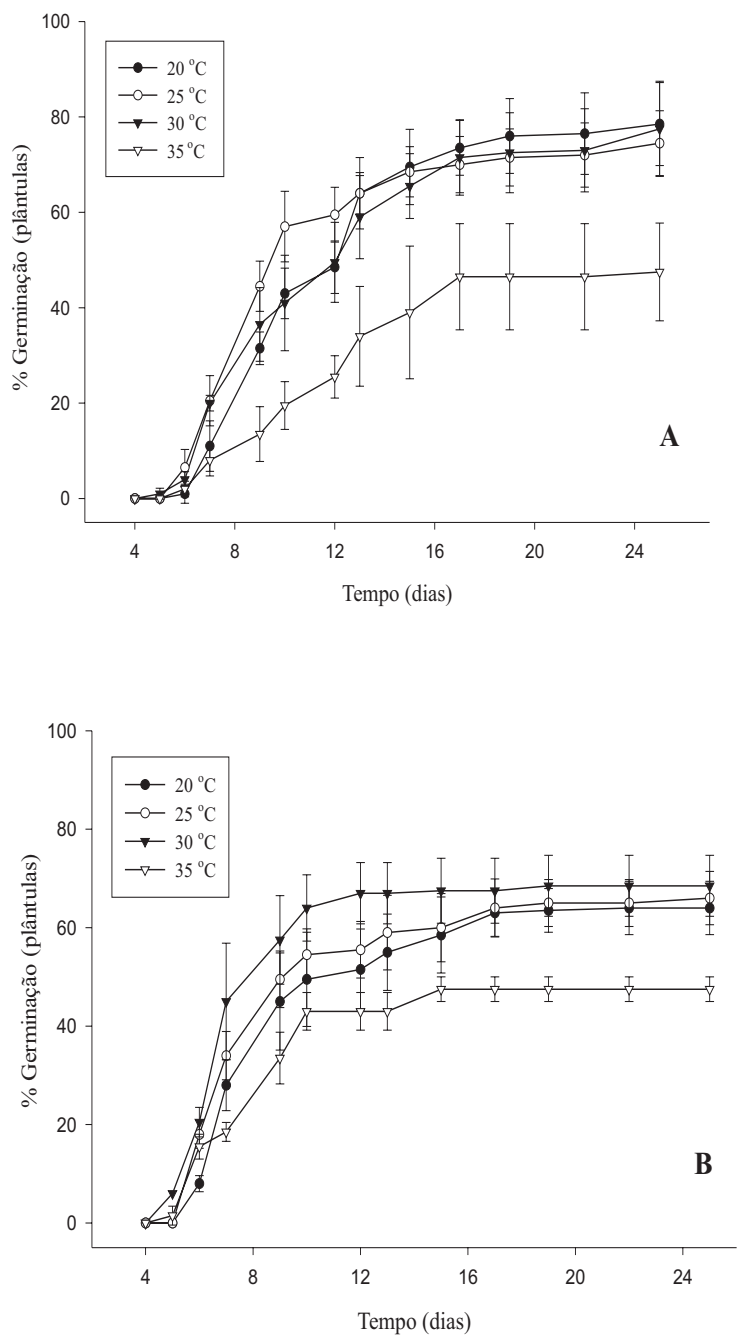

FIGURA 1. Germinação, considerando plântulas normais, para sementes de Eremanthus erythropappus para os lotes 2002 (A) e 2001 (B) a diferentes temperaturas. 
TABELA 5. Resultados do teste de germinação de dois lotes de sementes de Eremanthus erythropappus sob 4 regimes de temperatura

\begin{tabular}{cccccc}
\hline \multirow{2}{*}{ Critério } & \multirow{2}{*}{ Lote } & \multicolumn{4}{c}{ Temperatura $\left({ }^{\circ} \mathrm{C}\right)$} \\
\cline { 3 - 6 } & 2002 & $80,00 \mathrm{aA}$ & $78,00 \mathrm{aA}$ & $81,00 \mathrm{aA}$ & 35 \\
\hline Protrusão de raiz & 2001 & $76,50 \mathrm{aA}$ & $76,00 \mathrm{aA}$ & $76,00 \mathrm{aA}$ & $73,00 \mathrm{aA}$ \\
$(\%)$ & 2002 & $78,00 \mathrm{aA}$ & $74,00 \mathrm{aA}$ & $77,50 \mathrm{aA}$ & $47,50 \mathrm{aB}$ \\
\hline Plântulas & $64,00 \mathrm{bA}$ & $66,00 \mathrm{bA}$ & $68,50 \mathrm{aA}$ & $47,50 \mathrm{aB}$ \\
normais (\%) & 2001 & $3,755 \mathrm{aA}$ & $4,072 \mathrm{aA}$ & $3,875 \mathrm{bA}$ & $2,185 \mathrm{bB}$ \\
\hline IVG (plântulas) & 2002 & $3,756 \mathrm{aB}$ & $4,127 \mathrm{aAB}$ & $4,746 \mathrm{aA}$ & $2,989 \mathrm{aC}$ \\
\hline Plântulas & 2001 & $2,00 \mathrm{aA}$ & $4,00 \mathrm{aA}$ & $3,50 \mathrm{aA}$ & $26,50 \mathrm{aB}$ \\
anormais (\%) & 2002 & $12,50 \mathrm{bA}$ & $10,00 \mathrm{aA}$ & $7,50 \mathrm{aA}$ & $26,00 \mathrm{aB}$ \\
\hline Sementes mortas & 2002 & $3,00 \mathrm{aA}$ & $3,00 \mathrm{aA}$ & $1,00 \mathrm{aA}$ & $9,50 \mathrm{bB}$ \\
$(\%)$ & 2001 & $9,50 \mathrm{bB}$ & $8,00 \mathrm{bB}$ & $5,50 \mathrm{bAB}$ & $2,00 \mathrm{aA}$ \\
\hline Sementes duras & 2002 & $1,50 \mathrm{aAB}$ & $3,00 \mathrm{bB}$ & $2,00 \mathrm{aAB}$ & $0,00 \mathrm{aA}$ \\
$(\%)$ & 2001 & $0,50 \mathrm{aA}$ & $1,00 \mathrm{aA}$ & $1,50 \mathrm{aA}$ & $2,00 \mathrm{bB}$ \\
\hline
\end{tabular}

Sementes vazias ao final dos testes: lote $2002=16,25 \%$; lote $2001=17,00 \%$.

Médias seguidas pelas mesmas letras maiúsculas na linha e minúsculas na coluna (dentro do mesmo critério de avaliação) são iguais pelo teste de Tukey a 5\% de probabilidade.

estes se mostram iguais ou inferiores ao de $30^{\circ} \mathrm{C}$ (Tabela 6).

Com relação ao número de sementes mortas, foi observado aumento no número das mesmas sob temperaturas de 20,25 e $35^{\circ} \mathrm{C}$ (Tabela 5). A porcentagem de sementes duras encontradas ao final de 24 dias do teste de germinação foi baixa chegando às vezes a ser igual a zero (Tabela 5), mostrando que estas sementes não apresentam dormência.

Mesmo após o processo de limpeza utilizado (soprador), ainda foi observada média de $16,62 \%$ de sementes vazias entre os lotes, valores inferiores aos encontrados anteriormente, de 48\% (Davide e Tonetti, 2003), quando as sementes não passaram por processos de separação. Os resultados (Tabela 5) provam que a baixa qualidade fisiológica relatada anteriormente deve-se à ocorrência natural de sementes vazias nesta espécie, sendo pouco provável a ocorrência de dormência ou morte das sementes por secagem.

Sensibilidade à luz e temperatura alternada

A presença ou ausência de luz não inibe a germinação, discordando do trabalho de Chaves e Ramalho (1996), no qual não foi observada germinação de sementes de Eremanthus erythropappus no escuro. Os resultados (considerando as avaliações de protrusão de raiz) não seguiram tendência quando observados os tratamentos com temperatura de $30^{\circ} \mathrm{C}$, enquanto que no tratamento com alternância de temperatura e luz foram observados os maiores valores (Tabela 7). Quanto às plântulas normais (Tabela 8) e $U_{75-25}$ (Tabela 9), a temperatura alternada também gerou os melhores resultados, mostrando ser esta condição a mais adequada para germinação destas sementes.

TABELA 6. Valores de $T_{50}$ e $U_{75-25}$, durante a germinação de sementes de e Eremanthus erythropappus, a diferentes temperaturas

\begin{tabular}{cccccc}
\hline \multirow{2}{*}{ Critério avaliado Lote } & \multicolumn{5}{c}{ Temperatura $\left({ }^{\circ} \mathrm{C}\right)$} \\
\cline { 3 - 6 } & & 20 & 25 & 30 & 35 \\
\hline G. Max. & 2002 & 78,5 & $\underline{74,5}$ & $\underline{77,5}$ & 47,5 \\
$(\%)$ & 2001 & $\underline{64,0}$ & $\underline{66,0}$ & $\underline{68,5}$ & 47,5 \\
\hline $\mathrm{T}_{50}$ & 2002 & $\underline{9,90}$ & 8,18 & $\underline{10,00}$ & 11,12 \\
(dias) & 2001 & $\underline{7,32}$ & 6,87 & $\underline{6,54}$ & 7,35 \\
\hline $\mathrm{U}_{75-25}$ & 2002 & $\underline{4,47}$ & 3,42 & $\underline{5,60}$ & $\underline{5,84}$ \\
(dias) & 2001 & $\underline{\underline{2,83}}$ & 2,85 & $\underline{1,89}$ & 3,01 \\
\hline
\end{tabular}

Médias sublinhadas numa mesma linha indicam semelhança com os resultados obtidos na temperatura de $30^{\circ} \mathrm{C}$, pelo teste $\mathrm{T}$ com $0,01<\mathrm{p}<0,05$.

TABELA 7. Porcentagens médias de germinação (protrusão da raiz) e IVG de dois lotes de sementes de Eremanthus erythropappus sob 3 regimes de temperatura e luz

\begin{tabular}{lcccc}
\hline \multirow{2}{*}{ Critério avaliado } & \multirow{2}{*}{ Lote } & \multicolumn{3}{c}{ Tratamento } \\
\cline { 3 - 5 } & & $20-30^{\circ} \mathrm{C} / 10 \mathrm{~h}$ luz & $30^{\circ} \mathrm{C} 24 \mathrm{~h}$ luz & $30^{\circ} \mathrm{C} 24 \mathrm{~h}$ escuro \\
\hline Protrusão de raiz & 2002 & $95,00 \mathrm{aA}$ & $88,00 \mathrm{aAB}$ & $79,00 \mathrm{aB}$ \\
& 2001 & $62,00 \mathrm{bA}$ & $50,50 \mathrm{bA}$ & $47,00 \mathrm{bA}$ \\
\hline \multirow{2}{*}{ IVG (raiz) } & 2002 & $9,821 \mathrm{aA}$ & $6,544 \mathrm{aB}$ & $8,459 \mathrm{aA}$ \\
& 2001 & $9,328 \mathrm{bA}$ & $4,838 \mathrm{bB}$ & $5,275 \mathrm{bAB}$ \\
\hline
\end{tabular}

Médias seguidas pela mesma letra maiúscula na linha e minúscula na coluna (dentro de um mesmo critério) são iguais pelo teste de Tukey a $5 \%$. 
TABELA 8. Porcentagens médias de germinação (plântulas normais) de dois lotes de sementes de Eremanthus erythropappus, sob dois regimes de temperatura e luz

\begin{tabular}{ccc}
\hline \multirow{2}{*}{ Lote } & \multicolumn{2}{c}{ Condição de germinação } \\
\cline { 2 - 3 } & $20-30^{\circ} \mathrm{C} / 10 \mathrm{~h}$ de luz & $30^{\circ} \mathrm{C} / 24 \mathrm{~h}$ de luz \\
\hline 2002 & $90,00 \mathrm{aA}$ & $75,00 \mathrm{aB}$ \\
2001 & $56,00 \mathrm{bA}$ & $44,00 \mathrm{bB}$ \\
\hline
\end{tabular}

Médias seguidas pela mesma letra maiúscula na linha e minúscula na coluna são iguais pelo teste de Tukey a 5\%.

TABELA 9. Valores de $T_{50}$ e $U_{75-25}$ (uniformidade) durante a germinação de sementes de Eremanthus erythropappus, em temperaturas de $30^{\circ} \mathrm{C}$ com luz constante e $20-30^{\circ} \mathrm{C}$ com 10 horas de luz

\begin{tabular}{lccc}
\hline \multirow{2}{*}{$\begin{array}{l}\text { Critério } \\
\text { avaliado }\end{array}$} & \multirow{2}{*}{ Lote } & \multicolumn{2}{c}{ Condição de temperatura e luz } \\
\cline { 3 - 4 } & & $20-30 / 10 \mathrm{~h}$ de luz & $30^{\circ} \mathrm{C} /$ luz constante \\
\hline \multirow{2}{*}{ G. Max. (\%) } & 2002 & 90,00 & 75,00 \\
& 2001 & 56,00 & 44,00 \\
\hline \multirow{2}{*}{$\mathrm{T}_{50}$ (dias) } & 2002 & $\underline{6,94}$ & $\underline{7,82}$ \\
& 2001 & 5,07 & 6,32 \\
\hline \multirow{2}{*}{$\mathrm{U}_{75-25}$ (dias) } & 2002 & 2,72 & 8,80 \\
& 2001 & 2,23 & 3,47 \\
\hline
\end{tabular}

Médias sublinhadas numa mesma linha indicam semelhança entre os resultados pelo teste $\mathrm{T}$ com $0,01<\mathrm{p}<0,05$.

A melhor resposta das sementes às condições de alternância de temperatura e luz é freqüentemente encontrada em sementes de espécies nativas que apresentam dormência (Coperland e McDonald, 1999; Carvalho e Nakagawa, 1988). No entanto, a alternância de temperatura pode promover a aceleração do processo germinativo de sementes não dormentes (Coperland e McDonald, 1999), como foi observado para sementes desta espécie.

Independente da temperatura usada, a protrusão de raiz começou no terceiro dia, tempo menor que o encontrado por Chaves e Ramalho (1996) que a observaram após oito dias de embebição. Logo após a protrusão da raiz (quatro dias de embebição), apareceram as primeiras plântulas que atingiram os valores máximos em 14 dias, sob condições de alternância de temperatura e luz (Figura 2).

\section{Determinação da curva de embebição}

As curvas de embebição (Figura 3) seguiram o padrão trifásico proposto por Bewley e Black (1994). A umidade inicial das sementes foi de 5,23\%. As curvas obtidas (Figura 3) apresentaram rápida fase I de embebição, que ocorreu de 0 a 6 horas para as três condições testadas, quando as sementes atingiram aproximadamente $35 \%$ de água. A fase II da embebição prolongou-se até 72 horas, chegando a teor de

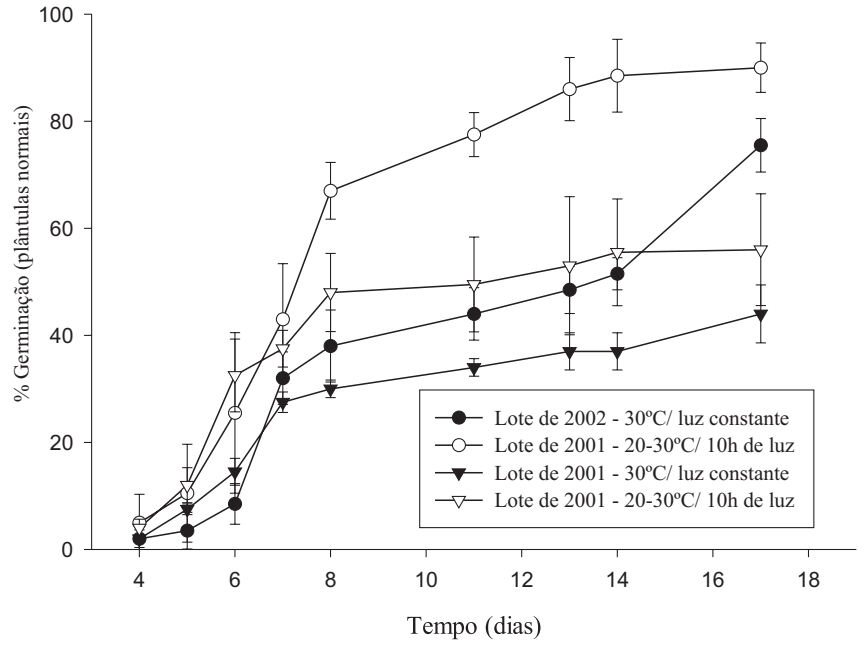

FIGURA 2. Germinação, considerando plântulas normais, para sementes de Eremanthus erythropappus, sob 2 condições de temperatura e luz.

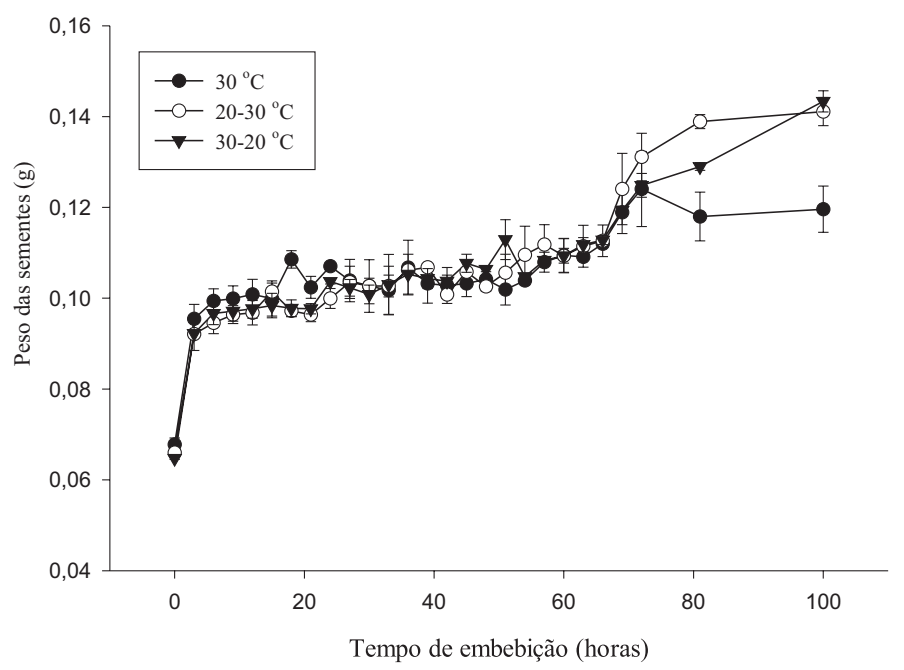

FIGURA 3. Curvas de embebição das sementes de Eremanthus erythropappus, sob temperatura de $30^{\circ} \mathrm{C}$ e luz constante e temperatura alternada de $20-30^{\circ} \mathrm{C}$ e 30 $20^{\circ} \mathrm{C}\left(10\right.$ horas de luz a $30^{\circ} \mathrm{C}$ e 14 horas de escuro a $\left.20^{\circ} \mathrm{C}\right)$.

água de aproximadamente $50 \%$. Os valores de umidade encontrados sugerem que as sementes apresentam tecido de reserva cotiledonar, pois de acordo com Coperland e McDonald (1999), sementes com este tipo de reserva devem atingir entre 35 e $40 \%$ e 50 e $60 \%$ de água ao final das fases I e II, respectivamente. A proporção de tempo decorrido entre as fases I e II está de acordo com Bewley (1997), que relata que, normalmente, a fase II dura até dez vezes mais que a fase I. A partir de aproximadamente 72 horas, iniciou-se a fase III de embebição, tal fase é marcada pela retomada do 
crescimento da raiz através dos processos de elongação e divisão celular.

Até o início da fase III, não foram detectadas diferenças no comportamento das sementes nas diferentes condições em que as sementes foram colocadas para embeber. As diferenças somente foram visíveis após a protrusão da raiz. A partir daí, pode-se observar que a condição de alternância de temperatura e luz promoveu aumento no peso da semente, favorecendo o crescimento do eixo embrionário e das estruturas essenciais da plântula (Figura 3). É provável que temperaturas alternadas podem, também, influenciar as reações metabólicas durante a embebição, antes da protrusão da raiz, e seus efeitos serem observados apenas após a germinação (Coperland e McDonald 1999).

\section{CONCLUSÕES}

A utilização de raios-x no procedimento de $30 \mathrm{Kv}$ por 45 segundos é viável para avaliação da qualidade física de sementes de Eremanthus erythropappus.

A utilização de soprador tipo South Dakota, regulado na abertura 6,0 e tempo de 30 segundos, foi eficiente para separar sementes vazias em lotes de sementes de Eremanthus erythropappus.

A condição ótima para germinação de sementes de Eremanthus erythropappus é $20-30^{\circ} \mathrm{C}\left(10\right.$ horas de luz a $30^{\circ} \mathrm{C}$ e 14 horas de escuro a $20^{\circ} \mathrm{C}$ ). Os testes de germinação podem ser conduzidos sobre papel de filtro, em gerbox. A primeira e a última contagens devem ser aos 6 e 14 dias, respectivamente.

A embebição de água das sementes de Eremanthus erythropappus nas temperaturas de $30^{\circ} \mathrm{C}, 20-30^{\circ} \mathrm{C}$ e $30-20^{\circ} \mathrm{C}$ é semelhante. Todas as condições apresentam fase I de 6 horas e o tempo de embebição decorrido até a fase II é de 72 horas. A partir da fase III de embebição, a alternância de temperatura de $20-30^{\circ} \mathrm{C}$ exerce influência positiva no desenvolvimento das plântulas.

\section{REFERÊNCIAS}

BEWLEY, J.D. Seed germination and Dormancy. The Plant Cell, Rockville, v. 9, n. 7, p. 1055-1066, 1997.

BEWLEY, J.D.; BLACK, M. Seeds: physiology of development and germination. 2. ed .: New York and London: Plenum Press, $1994.445 \mathrm{p}$

BONZANINI NETO, P. Histórico sobre os raios-x. Diponível em:
$<$ http://www.dominiobucal.com.br/histrx.htm>. Acesso em: 29 mai 2003.

BRASIL. Ministério da Agricultura e Reforma Agrária. Regras para análise de sementes. Brasília: SNDA/DNDV/CLAV, 1992. 365 p.

CARVAlHO, M.M.; NAKAGAWA, J. Sementes: ciência tecnologia e produção. 3. ed. Campinas: Fundação Cargill, 1988. $424 \mathrm{p}$.

CHAVES, M.M.F.; RAMALHO, R.S. Estudos morfológicos em sementes, plântulas e mudas de duas espécies arbóreas pioneiras da família Asteraceae (Vanillosmopsis erythropappa Sch. Bip e Vernonia discolor (Spreng.) Less). Revista Árvore, Viçosa, v. 20, n. 1, p. 1-7, 1996.

COPERLAND, L.O.; MCDONALD, M.B. Principles of seed science and technology. London: Kluwer Academic Publishers, 1999. $409 \mathrm{p}$.

CORREA, M.P. Dicionário das plantas úteis do Brasil e das exóticas cultivadas. Rio de Janeiro: Ministério da Agricultura, Indústria e Comércio, 1984. v.1, 669 p.

DAVIDE, A.C.; TONETTI, O.AO. Germinação de sementes de Eremanthus erythropappus (Candeia) sob dois regimes de temperatura e luz. Informativo ABRATES, Londrina, v.13, n.3, p. $335,2003$.

INTERNATIONAL SEED TESTING ASSOCIATION International rules for seed testing. Zürich, 1993. 363p.

MACHADO, C.F.; CÍCERO, S.M. 'Aroeira-branca' (Lithraea molleoides (Vell. Engl. - Anacardiaceae) seed quality evaluation by the X-ray test. Scientia Agrícola, Piracicaba, v.60, n.2, p. 393 $397,2003$.

NAKAGAWA, J. Testes de vigor baseados na avaliação das plântulas. In: VIEIRA, R.D.; CARVALHO, N.M. (Ed.) Testes de vigor em sementes. Jaboticabal: FUNEP/UNESP, 1994. p. 49-86.

NEMAF, Núcleo de Estudos em Manejo Florestal. Sistema de Manejo para a Candeia (Eremanthus erythropappus e Eremanthus incanus). Disponível em: $<\mathrm{http} / /$ www.nucleoestudo.ufla.br/nemaf>. Acesso em 01 out 2003.

NOBREGA, L.H.P.; JÚNIOR, C.C.; RODRIGUES, T.J.D.; CARREGARI, S.M.R. Efeito da luz e da temperatura na germinação de sementes de camomila (Matricaria Recutita). Revista Brasileira de Sementes, Brasília, v. 17, n. 2, p. 137-140, 1995.

Avaliação da qualidade de sementes. Reportagem. Diponível em: $<$ http:/ www.seednews.inf.br/português/seed 53 / artigocapa53.html $>$. Acesso em 10 jun. 2003.

SIMAK, M. Testing of forest tree and shrub seeds by $\mathrm{x}$ radiography. In: INTERNATIONAL SEED TESTING ASSOCIATION. Tree and shrub seed handbook. Zürich .

SOUZA, J.R.P.; AGUILERA, D.B.; TAKAHASHI, L.S.A. Germinação de sementes de camomila (Matricaria chamomilla L. separadas com espalhante adesivo. Revista Brasileira de Sementes, Brasília, v. 23, n. 1, p. 285-289, 2001. (Comunicação técnica). 